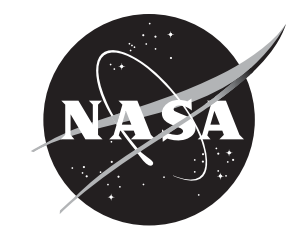

\title{
Fundamental Study of a Single Point Lean Direct Injector Part I: Effect of Air Swirler Angle and Injector Tip Location on Spray Characteristics
}

Sarah A. Tedder, Yolanda R. Hicks, Kathleen M. Tacina, and Robert C. Anderson Glenn Research Center, Cleveland, Ohio 


\section{NASA STI Program . . . in Profile}

Since its founding, NASA has been dedicated to the advancement of aeronautics and space science. The NASA Scientific and Technical Information (STI) program plays a key part in helping NASA maintain this important role.

The NASA STI Program operates under the auspices of the Agency Chief Information Officer. It collects, organizes, provides for archiving, and disseminates NASA's STI. The NASA STI program provides access to the NASA Aeronautics and Space Database and its public interface, the NASA Technical Reports Server, thus providing one of the largest collections of aeronautical and space science STI in the world. Results are published in both non-NASA channels and by NASA in the NASA STI Report Series, which includes the following report types:

- TECHNICAL PUBLICATION. Reports of completed research or a major significant phase of research that present the results of NASA programs and include extensive data or theoretical analysis. Includes compilations of significant scientific and technical data and information deemed to be of continuing reference value. NASA counterpart of peer-reviewed formal professional papers but has less stringent limitations on manuscript length and extent of graphic presentations.

- TECHNICAL MEMORANDUM. Scientific and technical findings that are preliminary or of specialized interest, e.g., quick release reports, working papers, and bibliographies that contain minimal annotation. Does not contain extensive analysis.

- CONTRACTOR REPORT. Scientific and technical findings by NASA-sponsored contractors and grantees.
- CONFERENCE PUBLICATION. Collected papers from scientific and technical conferences, symposia, seminars, or other meetings sponsored or cosponsored by NASA.

- SPECIAL PUBLICATION. Scientific, technical, or historical information from NASA programs, projects, and missions, often concerned with subjects having substantial public interest.

- TECHNICAL TRANSLATION. Englishlanguage translations of foreign scientific and technical material pertinent to NASA's mission.

Specialized services also include organizing and publishing research results, distributing specialized research announcements and feeds, providing information desk and personal search support, and enabling data exchange services.

For more information about the NASA STI program, see the following:

- Access the NASA STI program home page at http://www.sti.nasa.gov

- E-mail your question to help@sti.nasa.gov

- Phone the NASA STI Information Desk at 757-864-9658

- Write to:

NASA STI Information Desk

Mail Stop 148

NASA Langley Research Center

Hampton, VA 23681-2199 


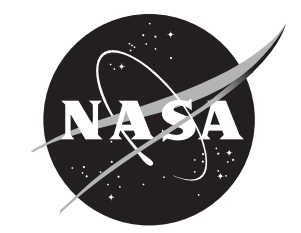

\section{Fundamental Study of a Single Point Lean Direct Injector Part I: Effect of Air Swirler Angle and Injector Tip Location on Spray Characteristics}

Sarah A. Tedder, Yolanda R. Hicks, Kathleen M. Tacina, and Robert C. Anderson Glenn Research Center, Cleveland, Ohio

Prepared for the

50th Joint Propulsion Conference

cosponsored by AIAA, ASME, SAE, and ASEE

Cleveland, Ohio, July 28-30, 2014

National Aeronautics and

Space Administration

Glenn Research Center

Cleveland, Ohio 44135 


\section{Acknowledgments}

This work was supported by the Supersonics and Aeronautical Sciences Projects of the NASA Fundamental Aeronautics Program. We also thank Aimee Bogner, Derek Podboy, and Kurt Rusmisel for their technical support.

This report contains preliminary findings, subject to revision as analysis proceeds.

Trade names and trademarks are used in this report for identification only. Their usage does not constitute an official endorsement, either expressed or implied, by the National Aeronautics and Space Administration.

Level of Review: This material has been technically reviewed by technical management.

Available from

NASA STI Information Desk

Mail Stop 148

NASA Langley Research Center

Hampton, VA 23681-2199
National Technical Information Service 5301 Shawnee Road Alexandria, VA 22312

Available electronically at http://www.sti.nasa.gov 


\title{
Fundamental Study of a Single Point Lean Direct Injector Part I: Effect of Air Swirler Angle and Injector Tip Location on Spray Characteristics
}

\author{
Sarah A. Tedder, Yolanda R. Hicks, Kathleen M. Tacina, and Robert C. Anderson \\ National Aeronautics and Space Administration \\ Glenn Research Center \\ Cleveland, Ohio 44135
}

\begin{abstract}
Lean direct injection (LDI) is a combustion concept to reduce oxides of nitrogen $\left(\mathrm{NO}_{\mathrm{x}}\right)$ for next generation aircraft gas turbine engines. These newer engines have cycles that increase fuel efficiency through increased operating pressures, which increase combustor inlet temperatures. $\mathrm{NO}_{\mathrm{x}}$ formation rates increase with higher temperatures; the LDI strategy avoids high temperature by staying fuel lean and away from stoichiometric burning. Thus, LDI relies on rapid and uniform fuel/air mixing. To understand this mixing process, a series of fundamental experiments are underway in the Combustion and Dynamics Facility at NASA Glenn Research Center. This first set of experiments examines cold flow (non-combusting) mixing using air and water. Using laser diagnostics, the effects of air swirler angle and injector tip location on the spray distribution, recirculation zone, and droplet size distribution are examined. Of the three swirler angles examined, $60^{\circ}$ is determined to have the most even spray distribution. The injector tip location primarily shifts the flow without changing the structure, unless the flow includes a recirculation zone. When a recirculation zone is present, minimum axial velocity decreases as the injector tip moves downstream towards the venturi exit; also the droplets become more uniform in size and angular distribution.
\end{abstract}

\section{Nomenclature}

$\begin{array}{ll}\text { CFD } & \text { computational fluid dynamics } \\ D_{t} & \text { venturi throat diameter } \\ F N_{U S} & \text { injector flow number } \\ h & \text { distance upstream of venturi throat } \\ \text { LDI } & \text { lean direct injection, lean direct injector } \\ \text { PIV } & \text { particle image velocimetry } \\ \text { PLS } & \text { planar laser scatter } \\ \text { r } & \text { distance from LDI exit } \\ S & \text { swirl number } \\ \text { SV } & \text { swirler venturi }\end{array}$

\section{Introduction}

For more than 40 years, NASA has sustained programs to reduce the environmental effects of aviation. A major focus of these programs has been reducing the emissions of nitrogen oxides $\left(\mathrm{NO}_{\mathrm{x}}\right)$. $\mathrm{NO}_{\mathrm{x}}$ emissions decrease the protective ozone layer in the stratosphere and increase smog and ozone in the lower troposphere (Ref. 1). To prevent damage to the protective ozone layer, NASA programs have focused on reducing $\mathrm{NO}_{\mathrm{x}}$ at cruise for supersonic flight. To reduce the emissions of $\mathrm{NO}_{\mathrm{x}}$ in the lower 
troposphere, NASA programs have also focused on reducing $\mathrm{NO}_{\mathrm{x}}$ emissions during the landing-takeoff cycle in subsonic flight.

In addition to decreasing $\mathrm{NO}_{\mathrm{x}}$ emissions, NASA has also addressed the reduction of carbon dioxide emissions by increasing engine fuel efficiency. Increased fuel efficiency is typically achieved by increasing the engine operating pressure ratio, which increases combustor inlet temperature; however, $\mathrm{NO}_{\mathrm{x}}$ formation rates increase with higher temperatures. Without an improvement in combustor technology, higher efficiency engines will have higher, not lower, $\mathrm{NO}_{\mathrm{x}}$ emissions. Therefore, improved low- $\mathrm{NO}_{\mathrm{x}}$ combustor technologies need to be developed.

In order to reduce $\mathrm{NO}_{\mathrm{x}}$ emissions, NASA is exploring fuel-lean front-end concepts. Historically, turbine engines for aircraft use rich-front-end combustors in order to ensure stable combustion in flight. In these combustors the primary combustion zone is fuel-rich - only part of the combustion air enters through the fuel/air mixers; the rest enters through downstream dilution jets, allowing combustion to be completed (Refs. 2 to 4). In contrast, lean-front-end combustors operate fuel-lean throughout: All of the combustor air except that used for liner cooling enters through the combustor dome. Lean front end combustion concepts include lean, premixed, prevaporized (LPP), lean partially premixed, and lean direct injection (LDI) combustion (Refs. 2, 5 to 9). This paper focuses on an LDI combustion concept.

LDI and other lean front end combustion concepts minimize local flame temperature. This keeps $\mathrm{NO}_{\mathrm{x}}$ emissions low because $\mathrm{NO}_{\mathrm{x}}$ is an exponential function of local temperature. To minimize $\mathrm{NO}_{\mathrm{x}}$ emissions, fuel-lean combustion needs to avoid local near-stoichiometric zones where the flame temperature is high. Avoiding these zones requires rapid and uniform fuel/air mixing. LDI accomplishes this mixing in part by replacing one traditionally-sized fuel/air mixer with multiple smaller fuel/air mixers. However, previous experiments have shown that decreasing the size and increasing the number of fuel/air mixers alone does not sufficiently improve mixing: fuel/air mixer design is also important.

Multiple fuel/air mixer designs have been studied. There are several ways an individual fuel/air mixer can be constructed. On the air side, a radial, axial, or discrete jet swirler may be used. With any of these types of swirlers, the swirl number can be varied. A venturi can be placed downstream of the air swirler, or the venturi can be omitted. On the fuel side, a simplex or air assist-atomizer can be used. For a simplex atomizer, flow number (i.e., effective flow area) can be varied. In addition, once a fuel/air mixer design has been chosen, the size and number of the mixer elements can be varied.

In order to choose the best fuel/air mixer design for an LDI combustor, it is critical to understand the fuel/air mixing process. Understanding fuel/air mixing requires knowledge both of large overall features such as recirculation zones and precessing vortices, and of smaller eddies where much of the mixing occurs. To better understand the mixing process, the NASA Fundamental Aeronautics/Aeronautical Sciences project is conducting a series of tests in the 5-atm Combustion and Dynamics Facility (CDF) flametube rig at NASA Glenn Research Center.

The baseline swirl-venturi (SV) LDI fuel/air mixer (Refs. 2 and 6) was used for these studies. The baseline SV-LDI fuel/air mixer consists of an axial swirler followed by a venturi. Fuel is injected through a simplex fuel injector; the fuel injector tip is at or just upstream of the venturi throat.

This first set of experiments examines cold flow mixing using water. It studies the effect of air swirler angle and fuel injector tip location on the cold flow droplet size and velocity fields. Testing was done at a temperature of $700 \mathrm{~K}$ and a pressure of $517-\mathrm{kPa}$. Water was used in place of jet fuel to prevent autoignition during long run times. Diagnostic measurements included particle image velocimetry, $30 \mathrm{kHz}$ high-speed video images of planar laser scatter, and shadowgraph images for droplet size measurement. The results from these measurements are used to examine the effects of air swirler angle and injector tip location on the spray distribution, recirculation zone, and droplet size distribution. 


\section{Experimental Facilities and Hardware}

\section{Combustion and Dynamic Facility (CDF)}

All testing was done at NASA Glenn Research Center in the Combustion and Dynamics Facility (CDF). A schematic of the CDF test rig is shown in Figure 1. The CDF is orientated vertically, with the flow going down. The CDF can supply non-vitiated air preheated up to $810 \mathrm{~K}$ at air flow rates up to $0.35 \mathrm{~kg} / \mathrm{sec}$ and pressures up to $517-\mathrm{kPa}$. The combustor test section has a circular cross-section nominally $7.62-\mathrm{cm}$ in diameter. Three sets of double-paned windows, spaced $90^{\circ}$ apart around its circumference, are used to gain optical access to the water-cooled combustor. The two opposing windows are aligned to provide access in the $\mathrm{x}$ direction, while the third window is on the $-\mathrm{y}$ side of the combustor. The windows are flat and have a small offset away from the combustor circumference. The windows measure $6.1-\mathrm{cm}$ tall (axial direction) by $5.8-\mathrm{cm}$ wide (azimuthal). Figure 2 shows a cross sectional detail drawing of the combustor, which defines the coordinate system and shows the window positions.

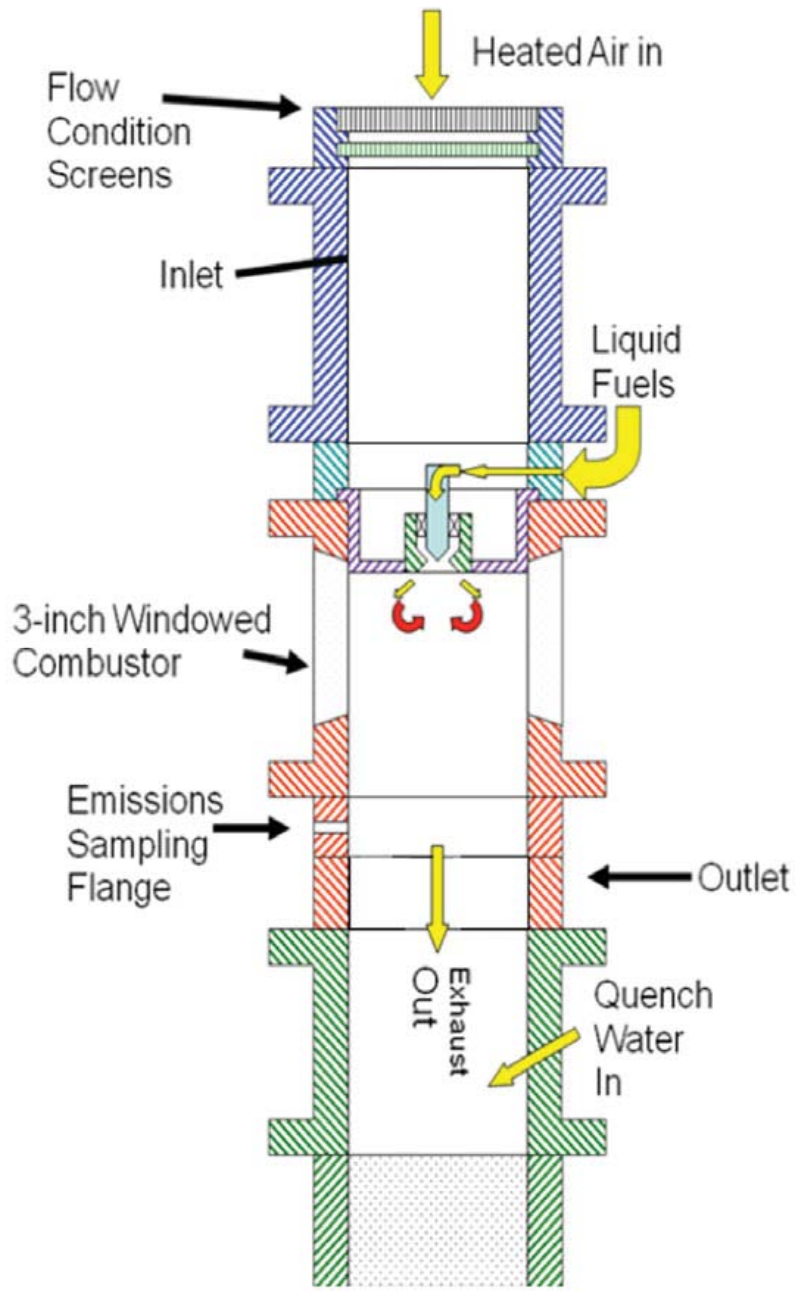

Figure 1.-Schematic of the test hardware. This schematic is not to scale.

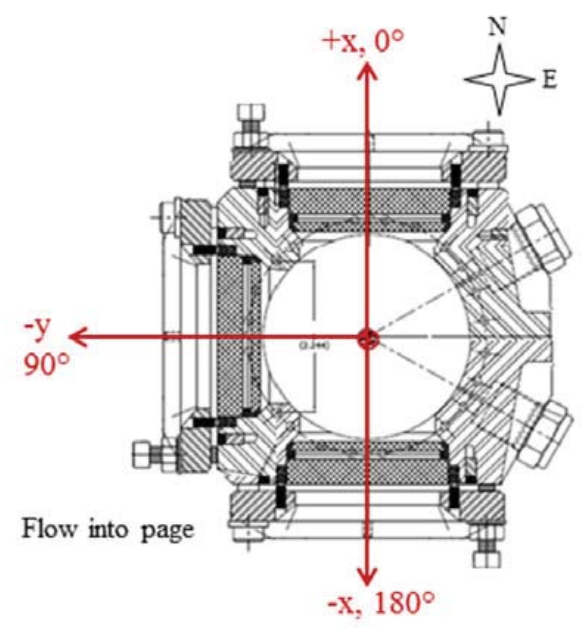

Figure 2.-Cross sectional detail of combustor. Shown by red arrows are the window orientation and definition of the coordinate system used. $Z$ is into the page. 


\section{LDI Hardware}

As illustrated in Figures 3 and 4, the baseline SV-LDI fuel/air mixer consists of a simplex pressureswirl fuel injector and an air passage with a six-bladed, helical axial air swirler followed by a convergingdiverging venturi section. The diameter of the venturi throat $\left(D_{t}\right)$ is $13.0 \mathrm{~mm}$. The simplex fuel injector is inserted through the center of the air swirler. The fuel injector tip is placed at one of three distances upstream of the venturi throat, h/ $\mathrm{D}_{\mathrm{t}}: 0,0.16$, or 0.31 throat diameters. The injector flow number, $F N_{U S}$, (as defined by Lefebvre (Ref. 10)) is 0.7 . The helical axial air swirlers have six blades. Each blade has an inside diameter of $9.4 \mathrm{~mm}$ and an outside diameter of $22 \mathrm{~mm}$. The blades angles for three configurations studied here are $45^{\circ}, 52.5^{\circ}$, and $60^{\circ}$. The calculated swirl numbers, as defined by Beer and Chigier (Ref. 11), are $0.59,0.77$, and 1.02 , respectively.

This baseline SV-LDI fuel/air mixer is nominally $2.54-\mathrm{cm}$ in diameter. However, the flametube is $7.62-\mathrm{cm}$ in diameter. In this study, the fuel/air mixer was mounted in the center of the flametube and surrounded by co-flow air; the co-flow enters the flametube through a screen that simulates the pressure drop across the fuel/air mixer. The test hardware is shown in Figure 4.

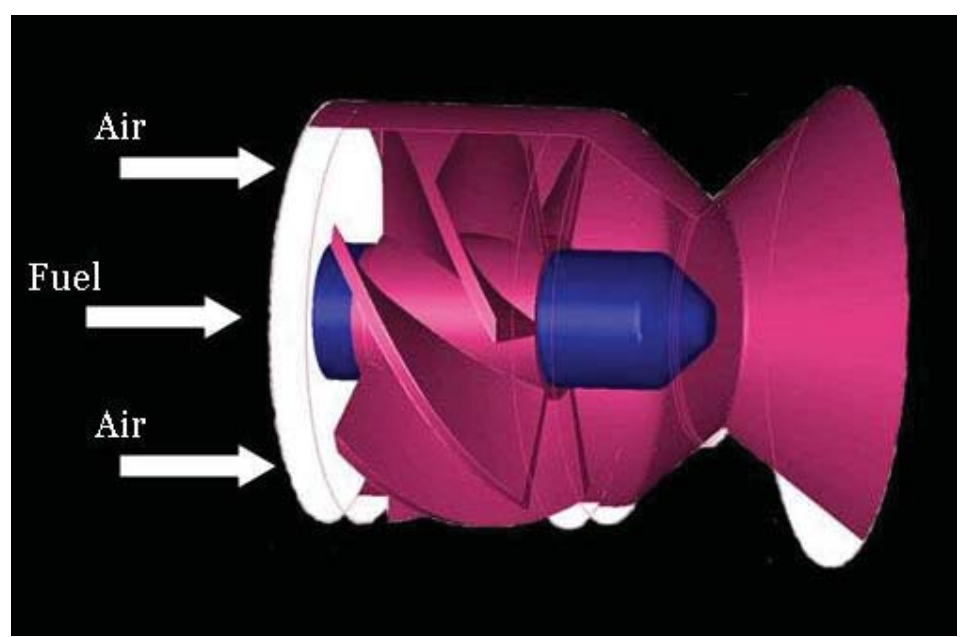

Figure 3.-Schematic drawing of a single SV-LDI fuel/air mixer.

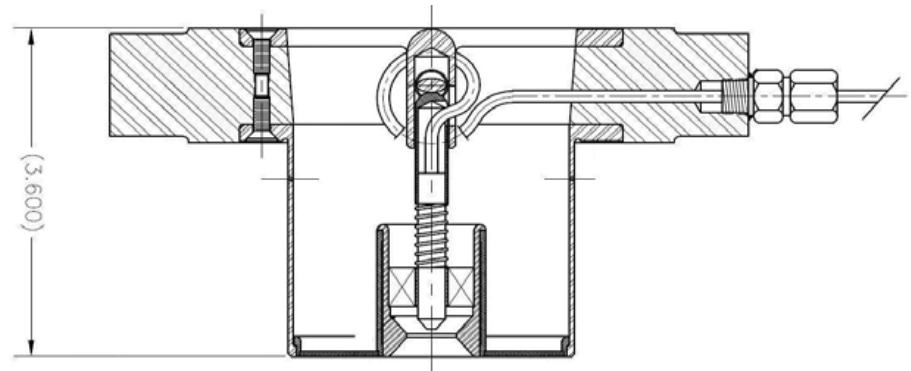

a)

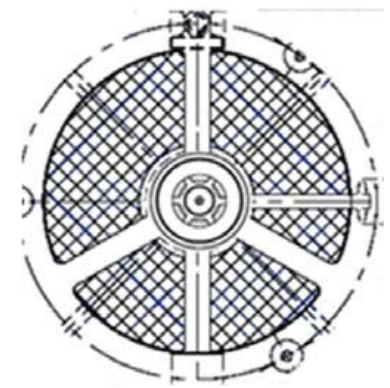

b)

Figure 4.-Cross section of the single SV-LDI module. Detailed drawings showing a cross section of the single SV-LDI module in its spool piece; (a) and a bottom view that shows the screen inserted around the module (b). 
TABLE 1.-TEST CONDITIONS

[Common conditions for both test points, 500 and 700: Air: Pressure $=517.1 \mathrm{kPa}$, Temperature $=700 \mathrm{~K}$.

The water was at room temperature, approximately $298 \mathrm{~K}$.

\begin{tabular}{|c|c|c|c|c|c|}
\hline Test point & $\begin{array}{c}\text { Reference velocity, } \\
\mathrm{m} / \mathrm{s}\end{array}$ & $\begin{array}{c}\text { Air flow rate, } \\
\mathrm{kg} / \mathrm{s}\end{array}$ & $\begin{array}{c}\text { Water flow rate, } \\
\mathrm{kg} / \mathrm{h}\end{array}$ & Water/Air ratio & $\begin{array}{c}\Delta P_{\text {injector, }} \\
\mathrm{kPa}\end{array}$ \\
\hline 500 & 9.1 & 0.107 & 3.89 & 0.100 & 672 \\
\hline 700 & 12.2 & 0.143 & 4.09 & 0.008 & 738 \\
\hline
\end{tabular}

\section{Test Conditions}

Results from two test conditions are presented in the results and discussion section. These test conditions will be referred to as test points 500 and 700. These conditions are detailed in Table 1 . The combustor air inlet temperature and pressure were the same for both test points $700 \mathrm{~K}$ and $517 \mathrm{kPa}$. The test point 500 has a lower reference velocity and a higher water to air ratio than the 700 test point. The water was injected at the same ambient temperature $(298 \mathrm{~K})$ for both test conditions.

\section{Optical Instrumentation}

For the work presented here, we measured water droplet velocities and sizes in preheated air. Two-dimensional velocity measurements were obtained using particle image velocimetry (PIV). The shadowgraph technique was used to obtain drop sizes and instantaneous velocity measurements of water spray. Planar laser scatter (PLS) was used to visualize liquid drops at a high frame rate and to develop limited pseudo time-series PIV. High frame rate PLS images were also used to develop spray pattern histograms. All techniques were laser-based. The lasers were located in a separate room and the light was transmitted to the test rig using mirrors, and then conditioned to the appropriate measurement volume via combinations of lenses. The details of the experimental setups are outlined below.

Standard PIV and PLS, used similar optical arrangements. The laser light for PIV and PLS entered and exited the combustor in the x-direction via the two opposing windows at $0^{\circ}$ and $180^{\circ}$, and the camera, which received the $90^{\circ}$-scattered light was positioned to collect the light via the window at $90^{\circ}$. For shadowgraphy, a line-of-sight technique, the light source and camera were positioned on opposite sides, using the two opposing windows.

PIV data were obtained using a dual head, frequency-doubled Nd:YAG laser operating at $15 \mathrm{~Hz}$. The laser pulse width was 3-5 ns. The spatially-overlapped laser beams were expanded into vertically-oriented sheets using a cylindrical lens. The sheets were approximately $45-\mathrm{mm}$-high by $0.3-\mathrm{mm}$ thick, entered the combustor through the $180^{\circ}$ window, and exited through the $0^{\circ}$ window. The sheet axis was aligned with the flow direction. Images were acquired through the $90^{\circ}$ window, collecting light scattered from water droplets that passed through the laser sheet, to capture liquid phase velocity. To collect the light, we used an $\mathrm{f}=105-\mathrm{mm}, \mathrm{f} / 4$ lens, outfitted with a 532-nm narrowband interference filter. An interline transfer CCD camera $(1600 \times 1200$ pixels $)$ captured the scattered light from adjacent laser pulses onto two individual frames. This collection scheme imaged a region that spanned roughly $50-\mathrm{mm}$ in the $\mathrm{x}$-direction (along the laser sheet axis) by 38 -mm axially (z-direction). The time between frames was typically $5 \mu \mathrm{s}$. All synchronization was handled using a LaVision, Inc. programmable timing unit, PTU-9. Crosscorrelation methods were then applied to create a displacement vector field for each image pair. LaVision's DaVis software version 7.2 was used to collect the images and version 8.2 was used to produce 2-D fields of the axial-horizontal ( $\mathrm{z}-\mathrm{x})$ velocity components in the $\mathrm{y}=0$ plane.

Shadowgraph images were produced using the same laser and camera. However, for the shadowgraph measurements the laser was expanded into a cone using a spherical lens, which in turn struck a fluorescent plate, producing a bright, yellow-orange background field. Light was collected on the opposite side with a long-range catadioptric microscope and stored on the camera. The system magnification was such that each image provided a field of view of approximately $2.2-\mathrm{mm}$ in the y-direction, by $1.7-\mathrm{mm}$ high (z-direction), with a depth of field of approximately 1-mm. Each image was considered to emanate 
from a "point" in space, and the whole optical system was traversed in 1- or 2-mm increments in the $\mathrm{x}$-direction, along $\mathrm{y}=0$, with occasional data collected along $\mathrm{x}=0$.

PLS images were acquired using a continuous wave Nd:YAG laser with a total power output of $\sim 1.1 \mathrm{~W}$. As with PIV, the laser beam was formed into a vertical sheet (approximately $40-\mathrm{mm}$ high, positioned along $\mathrm{y}=0$ ). The laser sheet entered via the $0^{\circ}$ window and exited through the $180^{\circ}$ window. We used a 12-bit, grayscale, high-speed camera that has a CMOS array with $1024 \times 1024$ pixel resolution. The high-speed camera was set up square to the rig and focused on the vertical plane at $y=0$. The highspeed camera frame rate and resolution are variable. The camera can frame as fast as 5400 -frames/s (5.4-kps) at full resolution (which provides the maximum field-of view image size), and faster at lower resolutions. A frame rate of $30-\mathrm{kps}$ and a resolution of $512 \times 352$ pixels was used. The light was collected using an $\mathrm{f}=60-\mathrm{mm}, \mathrm{f} / 2.8$ lens. The default exposure is $1 /($ frame rate), or $33.3 \mu \mathrm{s}$, which was used for all PLS images.

\section{Results and Discussion}

The effects of air swirler angle and injector tip location on the velocity field and droplet size distribution are presented in this section. First, we discuss effects of the air swirler angle on the spray distribution, droplet size, and recirculation zone. We then discuss the injector tip location effect on spray distribution, droplet size, and recirculation zone.

\section{Air Swirler Angle}

This subsection examines the effect of air swirler angle when the injector tip is located at the venturi throat.

\section{Spray Distribution}

An even distribution of droplets in the injector spray improves the mixing of fuel and oxidizer, reducing production of $\mathrm{NO}_{\mathrm{x}}$ by minimizing the occurrence of pockets of increased temperature caused by local peaks in fuel air ratio. One important parameter used to characterize the droplet distribution is the spray angle.

The spray angles can be observed qualitatively by examining the measured PIV velocity fields. Shown in Figure 5(a) to (c) are PIV velocity fields at $y=0$, at test condition 500, with the injector tip at the venturi throat. These results indicate qualitatively that the spray angle of the droplets increases with increasing swirler angle.

a)

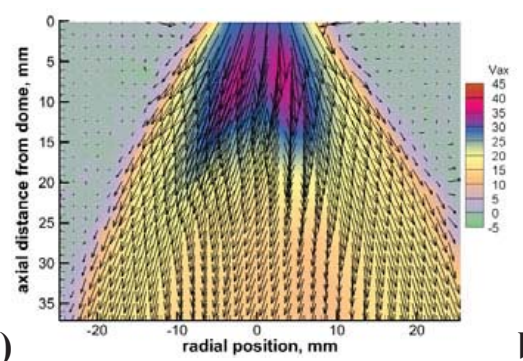

b)

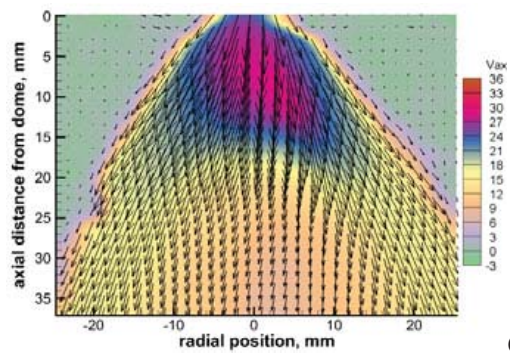

\section{c)}

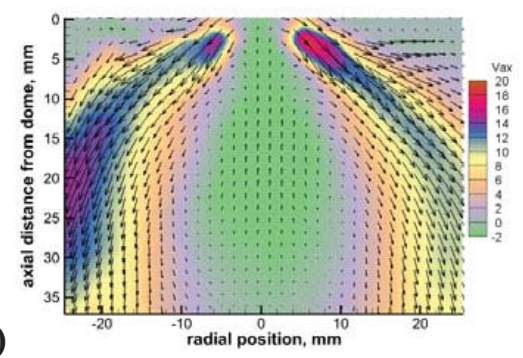

Figure 5.-Average Velocity Fields. Average velocity fields at $y=0$ for water spray measured with PIV measured at test condition 500 with injector tip at the venturi throat. Increasing air swirler angle from left to right: (a) $45^{\circ}$, (b) $52.5^{\circ}$, (c) $60^{\circ}$. The flow is from top to bottom. 
We also measured the spray pattern using the high-speed images of PLS. For each condition we analyzed 1000 high-speed image frames using IDL (Ref. 12) and software (Ref. 13) which finds and measures roughly circular features within an image. For each of the features, a distance, $r$, and angle relative to the vertical measured from $(\mathrm{x}, \mathrm{y}, \mathrm{z})=(0,0,0)$ were determined. Spray pattern histograms were developed by creating software "bins" which were $3^{\circ}$ wide with an $r$ that ranged from 10 to $30 \mathrm{~mm}$. The software counted the features found in each bin throughout the 1000 frames analyzed. Results of this analysis are shown in Figure 6, where all three plots are shown with the same scale. These histograms clearly indicate that the spray was a hollow cone, as expected from a simplex fuel injector. They also indicate that the number of droplets found in the center of the hollow cone increases with increasing swirler angle.

Using the droplet distribution histograms, we define the spray angle as the difference between the bin angle where the total count reached 5 percent and the angle where the count reached 95 percent. These calculated spray angles are plotted versus swirler angle in Figure 7. The trend in Figure 7 closely matches the trends observed in the PIV velocity field in Figure 5 (increasing spray angle with increasing swirler angle). In addition, in Figure 7, one can note that the spray angle is higher at point 500 than at point 700 for swirler angles of $45^{\circ}$ and $52.5^{\circ}$, but not for $60^{\circ}$.

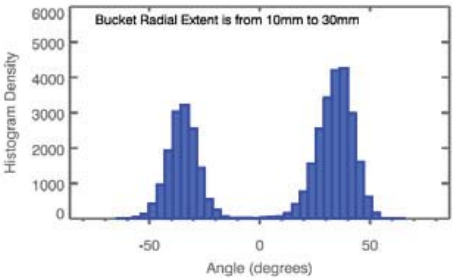

a)

Figure 6.-Histograms of Droplet Distributions. Occurrences of droplets at angles relative to center of air mixer exit at test condition 500 with injector tip at the venturi throat. Increasing air swirler angle from left to right: (a) $45^{\circ}$, (b) $52.5^{\circ}$, (c) $60^{\circ}$.

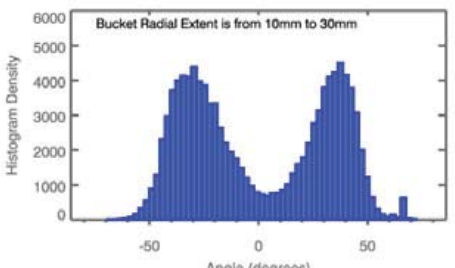

b)

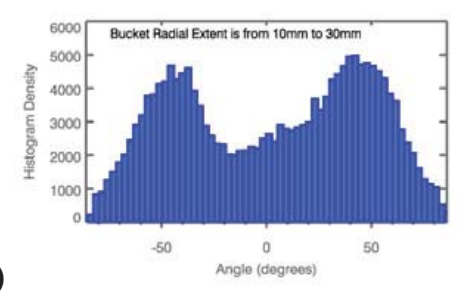

c) 


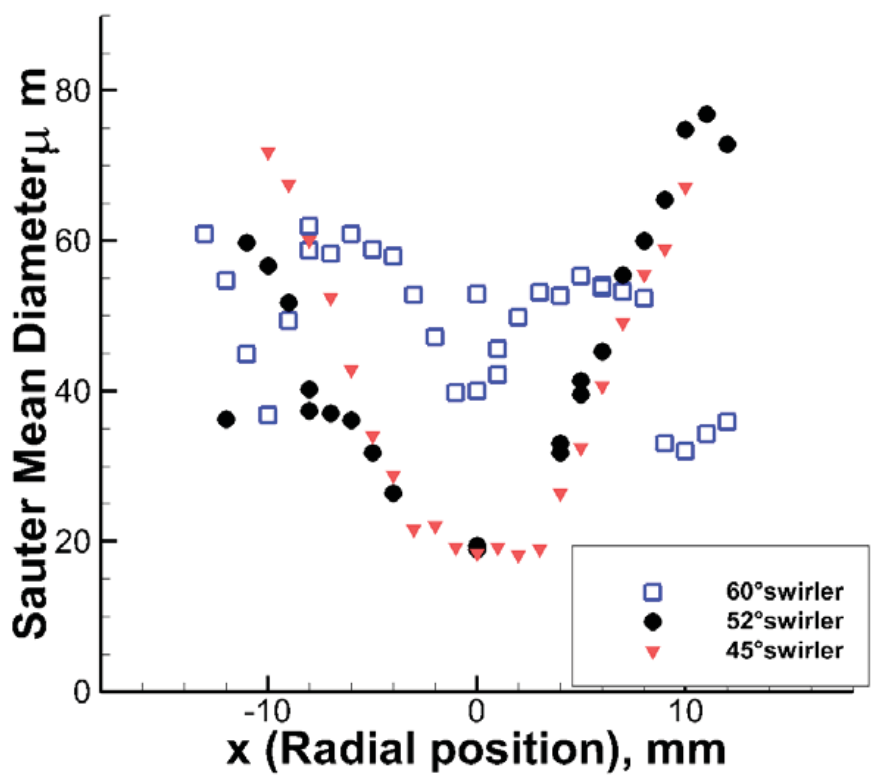

Figure 8.-Sauter mean diameter versus radial position. Plot of droplet diameter versus radial location, $x$, for test condition 500 with the injector tip at the throat of the venturi.

\section{Droplet Size}

The Sauter mean diameter (SMD) is plotted versus radial position for each swirler angle in Figure 8. These measurements were collected at test point 500 with the injector tip at the throat. The SMD is measured at points along a line perpendicular to the flow at an axial location, $z=11 \mathrm{~mm}$, downstream of venturi exit. The droplet size distribution is similar for swirler angles $45^{\circ}$ and $52.5^{\circ}$ with smaller droplets occurring towards the center of the spray and larger droplets near the outer edges. For these swirler angles the SMD ranges from $80 \mu \mathrm{m}$ to below $20 \mu \mathrm{m}$. For swirler angle $60^{\circ}$, the size distribution is narrower, spanning from 30 to $60 \mu \mathrm{m}$ across the scan. This may be a result of the presence of the recirculation zone produced by the $60^{\circ}$ swirler angle as discussed in the next section.

\section{Recirculation Zone}

In gas turbine combustors, swirl is used to improve fuel/air mixing and to mix the combustion products with the unburned fuel and air, thereby decreasing flame length and increasing flame stability. Usually, the swirl is strong enough to cause reverse flow and a central recirculation zone forms downstream of the fuel/air mixer (Ref. 10). Previous work on swirling jets has shown that a central recirculation zone forms when the swirl number is greater than about 0.6 (Refs. 10, 11, and 14). Furthermore, a diverging flow passage has been shown to increase the diameter and mass of fluid in the recirculation zone (Ref. 11).

Since the SV-LDI geometry includes a converging-diverging venturi, a central recirculation zone would be expected as long as the swirl number was near 0.6. Therefore, the minimum swirler vane angle was chosen to be $45^{\circ}$, corresponding to a swirl number of 0.59 (Ref. 6). However, subsequent optical diagnostic measurements (Ref. 15) and CFD calculations (Ref. 16) showed that with a swirler angle of $45^{\circ}$ no central recirculation zone formed. This was true both for a single 2.54-cm SV-LDI fuel/air mixer in a $2.54-\mathrm{cm}$ by $2.54-\mathrm{cm}$ square duct (Refs. 15 and 16) and an array of 3 by 3 fuel/air mixers in a $7.62-\mathrm{cm}$ by $7.62-\mathrm{cm}$ square duct (Ref. 16). In fact, the experiments conducted by Fu (Ref. 15) on a single 2.54-cm SV-LDI in the $2.54-\mathrm{cm}$ by $2.54-\mathrm{cm}$ square duct showed that a strong central recirculation zone did not form until the swirler angle was well above $45^{\circ}$. In this experiment, $\mathrm{Fu}$ (Ref. 15) varied the swirler angle 
from $40^{\circ}$ to $65^{\circ}$ in $5^{\circ}$ increments. No central recirculation zone formed until the swirler angle was $55^{\circ}$; and even then, the central recirculation zone did extend to the venturi exit - it started about 22-mm downstream of the venturi exit. The central recirculation zone did not extend to the venturi exit until the swirler angle was $60^{\circ}, \mathrm{S}=1.02$ (Ref. 15). For a 3 by 3 array of fuel/air $60^{\circ}$ swirler angle mixers, previous CFD calculations (Ref. 16) and experimental measurements (Ref. 17) also showed a recirculation zone extending to the venturi exit.

The experiment presented in this paper differs from these previous experiments (Refs. 15 to 17) as it was done on a single $2.54-\mathrm{cm} \mathrm{SV-LDI} \mathrm{fuel/air} \mathrm{mixer} \mathrm{in} \mathrm{a} \mathrm{7.62-cm} \mathrm{circular} \mathrm{duct.} \mathrm{A} \mathrm{single} \mathrm{fuel/air} \mathrm{mixer}$ was studied to allow for detailed measurements to be taken without interaction from surrounding fuel/air mixers. However, this means that the boundary conditions, i.e., confinement, were significantly different than it would be in a more realistic case of seven $2.54-\mathrm{cm}$ fuel/air mixers in the same $7.62-\mathrm{cm}$ circular duct. Previous research (Refs. 11, 14, 15, and 18) has shown that confinement can significantly affect the velocity field and recirculation zone. Therefore, to partially simulate the effects of multiple fuel/air mixers, a coflow was used. Although this experiment had a coflow whereas the previous research did not (Refs. 16 and 17), the current results are consistent: a recirculation zone was observed for the $60^{\circ}$ swirler but not for the $45^{\circ}$ swirler. There was also no recirculation zone for the $52.5^{\circ}$ swirler.

In this work the value and location of the minimum axial velocity for various swirler angles was used as an indicator of the effect swirler angle (shown in Fig. 9). This was done since the neither the $45^{\circ}$ swirler nor the $52.5^{\circ}$ swirler case produced a recirculation zone. Figure 9(a) shows that the minimum axial velocity decreases with increasing swirler angle. In Figure 9(b) for both the $45^{\circ}$ swirler and the $52.5^{\circ}$ swirler, the minimum axial velocity is at the downstream edge of the field of view, $\mathrm{z} \approx 36 \mathrm{~mm}$; this means that the actual location of the minimum axial velocity may be farther downstream and that the minimum velocity may be lower. For the $60^{\circ}$ swirler, the location of the minimum axial velocity (i.e., greatest reverse flow) is much farther upstream.

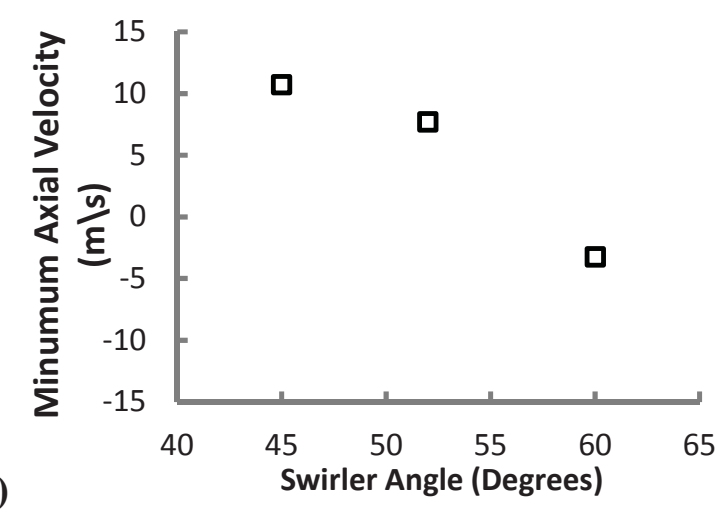

a)

Figure 9.-Effect of Swirler Angle on Minimum Axial Velocity. The injector tip is at the venturi throat and test condition is 500. Shown are a) minimum axial velocity and b) axial location of this minimum axial velocity versus swirler angle. 


\section{Injector Tip Location}

This subsection examines the effect of the injector tip location on spray distribution and droplet size distribution for all three swirler angles, and the recirculation zone for the $60^{\circ}$ swirler angle.

\section{Spray Distribution}

To examine the spray distribution, PIV results along the $y=0$ combustor position are shown at both conditions 500 and 700 in Figures 10 and 11 for swirler angle $45^{\circ}$, and in Figure 12 at test condition 500 for swirler angle $60^{\circ}$. The flow is from top to bottom. From left to right in these figures, $h / \mathrm{D}_{\mathrm{t}}$ is $0,-0.16$, and -0.31 . In Figures 10 and 11, the results show that the spray angle increases as the injector tip is moved farther upstream of the throat. For the $60^{\circ}$ swirler (Fig. 12), it is harder to discern by eye, but the trend appears to be opposite. A more quantitative consideration of the effect is shown in Figure 13, which shows plots of spray angle versus injector tip location calculated from the histograms as described in the spray distribution section above. These graphs show agreement with the visual observations made for the PIV images, and emphasize that there is only a minor change of spray angle for the $60^{\circ}$ air swirler with injector tip position (Fig. 13(c)).

a)

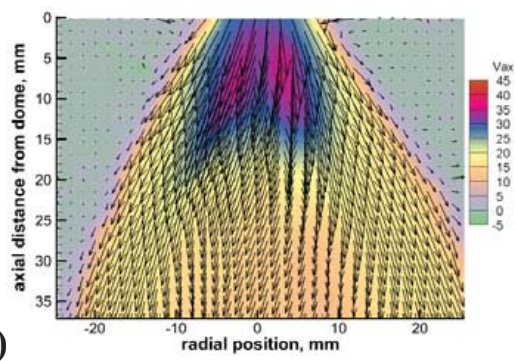

b)

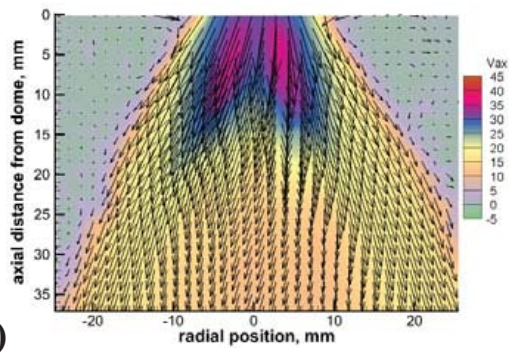

c)

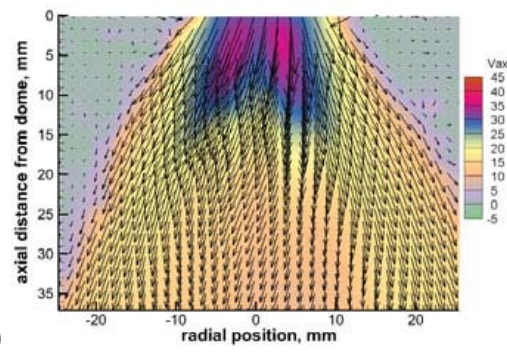

Figure 10.-Average Velocity Fields, $45^{\circ}$ swirler, Condition 500. Average velocity fields for water spray measured with PIV at test condition 500 with $45^{\circ}$ swirler angle. Injector tip distances upstream of the throat, $h / D_{t}$ are a) $\left.0, b\right) 0.16$, and c) 0.31. The flow is from top to bottom.

a)

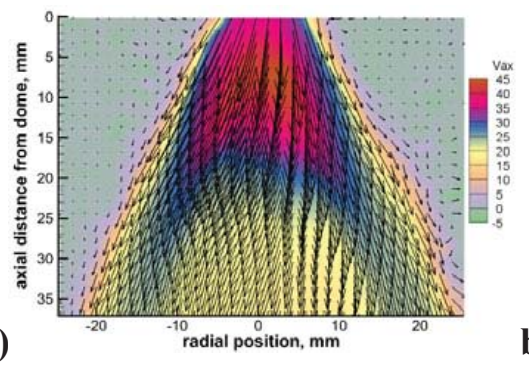

b)

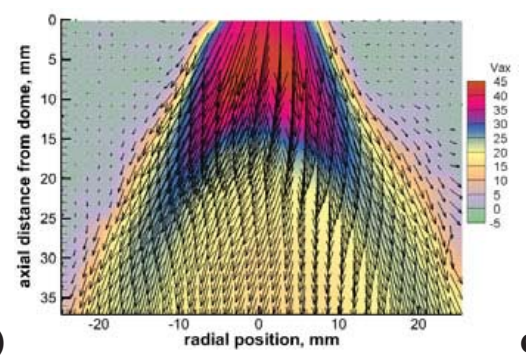

c)

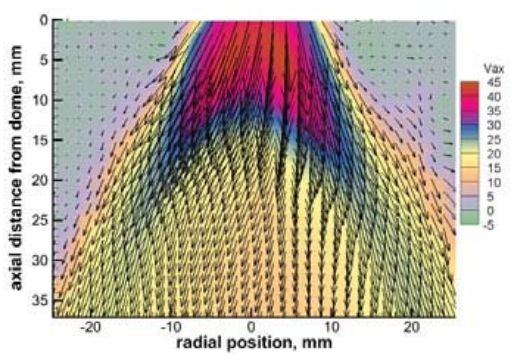

Figure 11.-Average Velocity Fields, $45^{\circ}$ swirler, Condition 700 . Average velocity fields for water spray measured with PIV at test condition 700 with $45^{\circ}$ swirler angle. Injector tip distances upstream of the throat, $h / D_{t}$ are a) $\left.0, b\right) 0.16$, and c) 0.31 . The flow is from top to bottom.

a)

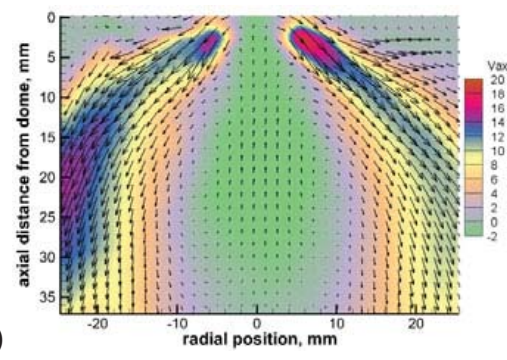

b)

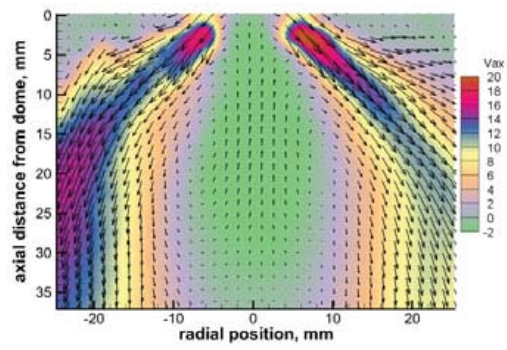

c)

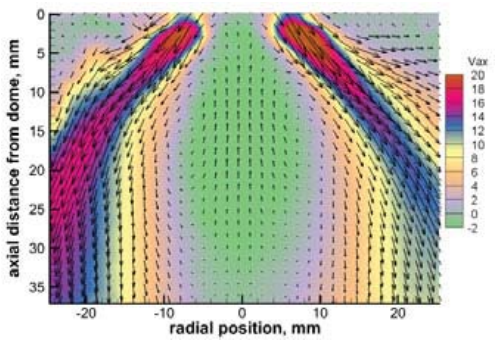

Figure 12.-Average Velocity Fields, $60^{\circ}$ swirler. Average velocity fields for water spray measured with PIV at test condition 500 with $60^{\circ}$ swirler angle. Injector tip distances upstream of the throat, $h / D_{t}$ are a) $\left.0, b\right) 0.16$, and c) 0.31 . The flow is from top to bottom. 

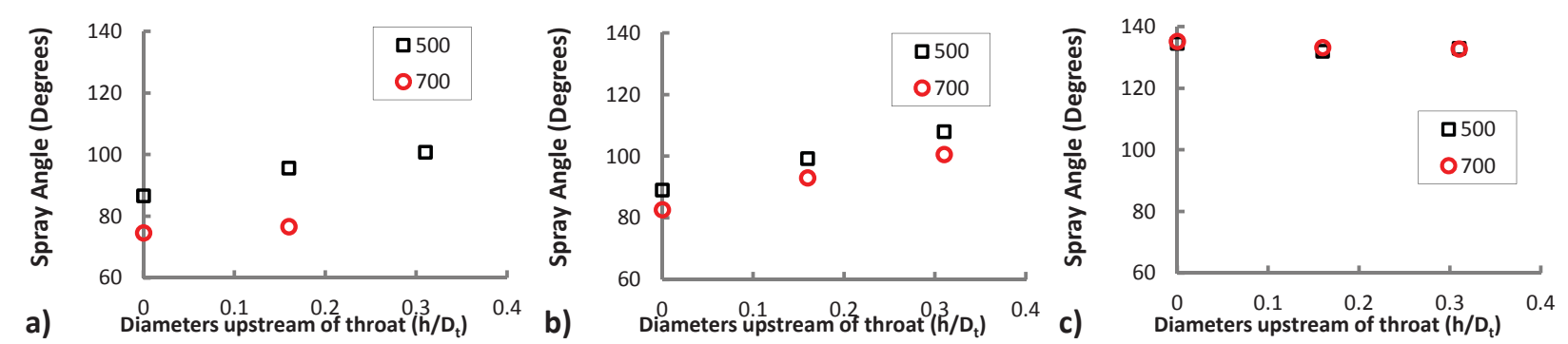

Figure 13.-Effect of Injector Tip Location on Spray Angle. Plots of spray angle versus location of injector tip diameter measured in $h / D_{t}$. From left to right the plots are for swirler angles $45^{\circ}, 52.5^{\circ}$, and, $60^{\circ}$.

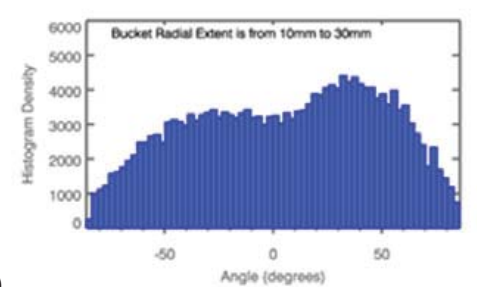

a)
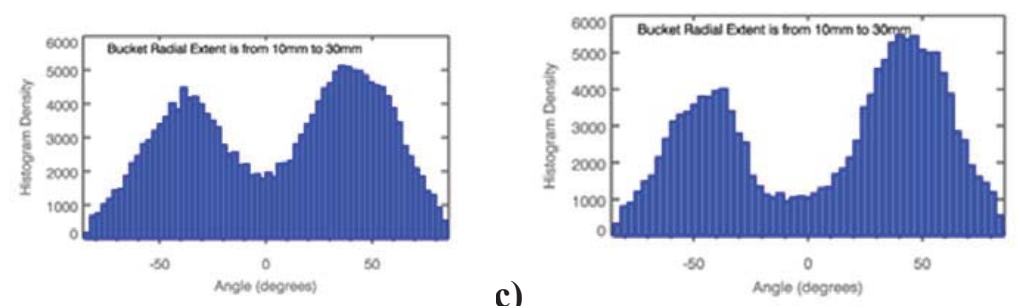

Figure 14.-Histograms of Droplet Distributions of Swirler Angle $60^{\circ}$. Occurrences of droplets at angles relative to center of air mixer exit at test condition 700 with injector tip at the venturi throat. Injector tip distance upstream of the throat in throat diameters: (a) at throat, (b) 0.16, (c) 0.31.

To understand the effect of the injector tip location further, the histograms from the $60^{\circ}$ swirler are examined. Figure 14(a) to (c) show histograms of the droplet distributions for the range of spray angles measured for test condition 700 with $\mathrm{h} / \mathrm{D}_{\mathrm{t}}$ of $0,-0.16$, and -0.31 . The histograms show that the distribution becomes more uniform as the injector tip is moved closer to the throat.

\section{Droplet Size}

Figure 15 shows the SMD for the various injector tip locations, measured across the flow at the axial location $\mathrm{z}=11 \mathrm{~mm}(11 \mathrm{~mm}$ downstream of venturi exit). The plots show that as the injector tip moves downstream the droplet sizes are larger in the center region of the of the flow from $\sim \mathrm{X}=-10 \mathrm{~mm}$ to $10 \mathrm{~mm}$. This is most evident for Figure 15(a) for swirler angle $60^{\circ}$, test condition 700 . This trend is also seen for Figure 15(b) for swirler angle 52.5 , test condition 700 . There are many possible reasons for increase in uniformity of the droplet sizes such as: a simple shift of the flow downstream or droplet coagulation. To determine the cause of these trends, droplets sizes need to be measured at several more axial locations.

\section{Recirculation Zone}

The recirculation zone generated using the $60^{\circ}$ swirler was characterized based on its size and minimum velocity. The velocity field for the $60^{\circ}$ swirler flow, as seen in Figure 12, shows that the region measured with the PIV in this experiment does not include the stagnation point of the recirculation zone. The field of view only includes the top portion of the primary zone as shown in the drawing representation of the flow in Figure 16. Because of this limited field of view, the outer bounds of the recirculation zone cannot be determined. Hence in order to measure the width of the recirculation zone, the zero velocity line is used instead. The maximum width of zero velocity area of the recirculation zone is plotted versus the injector tip location in Figure 17(a). This plot shows that the recirculation zone has a width that is almost constant, but is slightly wider with the injector tip at the throat. The location of this maximum width plotted versus the location of the injector tip is shown in Figure 17(b). The location shows a shifting of the maximum width downstream as the injector tip proceeds downstream, which reflects a simple shifting of the flow downstream. 


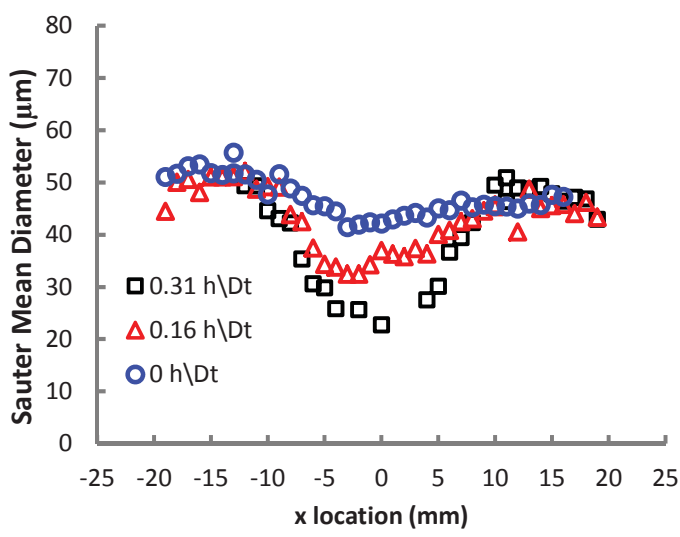

a)

Figure 15.-Droplet Size Distribution Effect of Injector Tip. a) Plot of droplet size verses versus $x$ (radial) location for a range of injector tip locations at test condition 700 and swirler angle $60^{\circ}$. b) Plot of droplet size versus radial location for a range of injector tip locations at test condition 700 and swirler angle 52.5०.

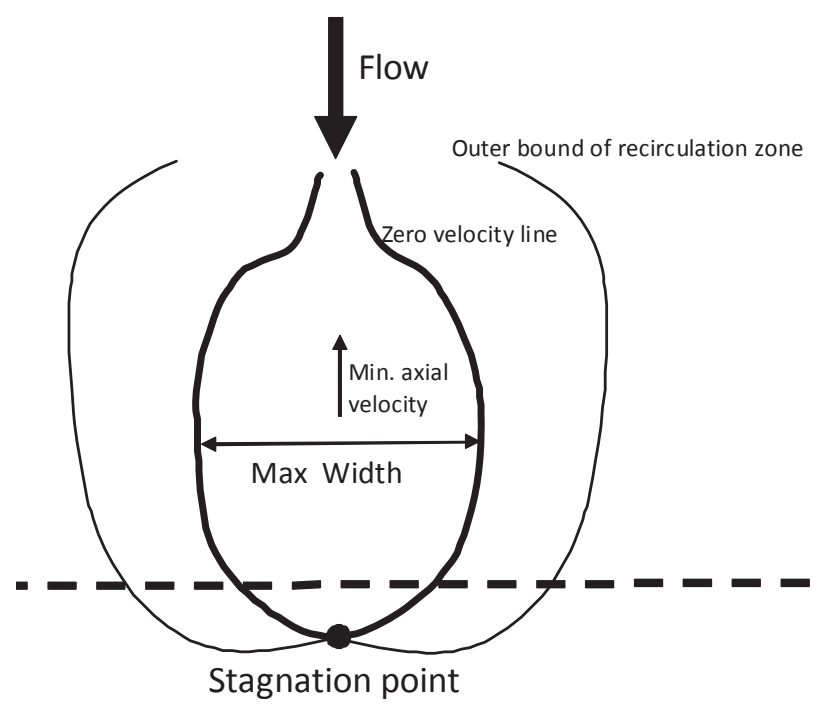

Figure 16.-Drawing of the recirculation zone. Drawing of the flow with a recirculation zone. The field of view for this experiment only include the area above the dashed line.

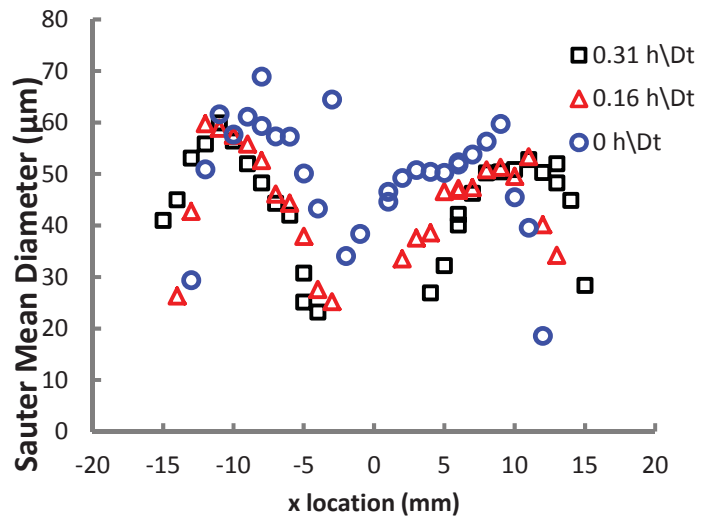

b)

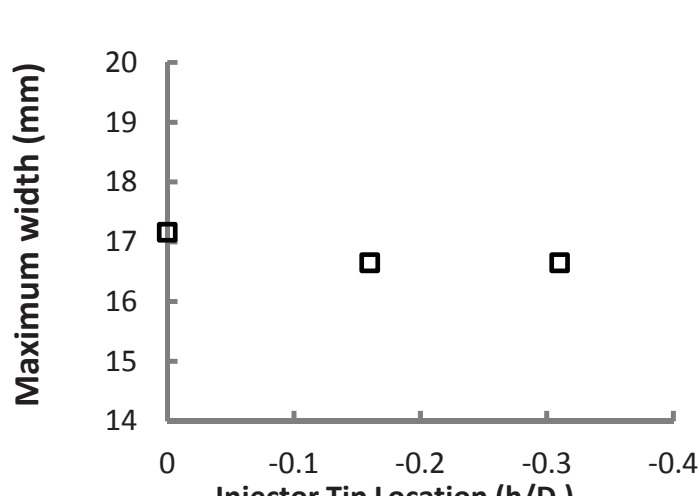

a) Injector Tip Location $\left(\mathrm{h} / \mathrm{D}_{\mathrm{t}}\right)$

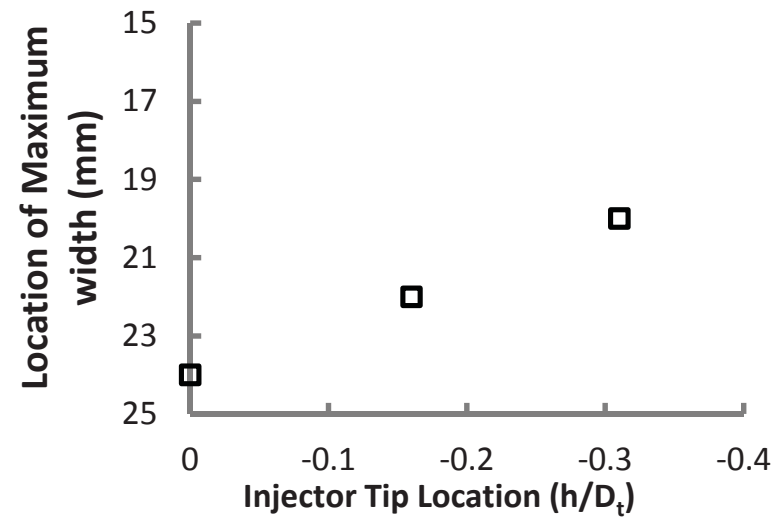

b)

Figure 17.-Measures of Recirculation Zone Size. a) Plot of maximum width versus injector tip location diameter upstream of throat. b) Plot of location of maximum width versus injector tip location. Swirler angle $60^{\circ}$ and test condition 500 . 


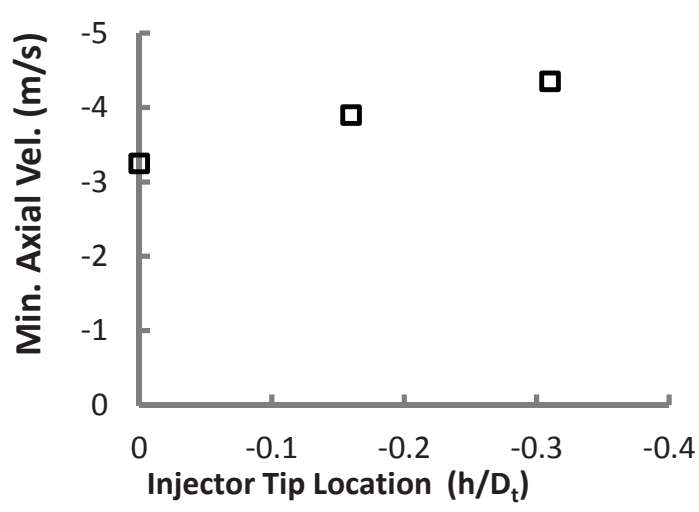

a)

Figure 18.-Measures of Strength of Recirculation for $60^{\circ}$ Swirler. a) Plot of minimum axial velocity and b) axial location of minimum velocity versus injector tip location. Test condition 500.

The minimum axial velocity of the recirculation zone was also measured and is shown in Figure 18. Figure 18(a) shows that the minimum axial velocity increases as the injector tip is moved further upstream the throat. This trend shows that the location of the injector tip may have an effect on the flow structure when a recirculation zone is present. The location of this maximum reverse flow is shown in Figure 18(b) plotted against the location of the injector tip. This plot shows a shifting of the maximum velocity downstream as the injector tip is moved downstream.

\section{Summary}

The swirler angle has a large effect on the spray angle and the formation of a recirculation zone as shown in References 15, 19, and 20. The larger the swirler angle the wider the spray angle and the more likely the formation of the recirculation zone. Recirculation only occurred for swirl number $\mathrm{S}=1.02$, corresponding to the $60^{\circ}$ swirler. The injector tip location appears to only shift the flow without changing the structure for most flows. For flows with a recirculation zone, the droplets became more uniform in size and angular distribution the closer the injector tip was to the venturi throat. This relationship between injector tip location and recirculation zone was also shown by considering the minimum axial velocity. The minimum axial velocity increases as the injector tip was moved upstream towards the venturi throat.

\section{References}

1. Lee, D.S., Pitari, G., Grewe, V., Grierens, V., Penner, J.E., Petzold, A., Prather M.J., Schumann, U., Bais, A., Berntsen, T., Iachetti, D., Lim, L.L., and Sausen, R., "Atmospheric Environment," Vol. 44, pp. 4678-4734, 2010.

2. Tacina, R.R., "Low-NOx potential of gas turbine engines," AIAA-1989-0550, 1989.

3. Chang, C.T. and Holdeman, J.D., "Low emissions RQL flametube combustor test results," NASA/TM-2001-211107, 2001.

4. Peterson, C.O., Sowa, W.A., and Samuelson, G.S., "Performance of a model rich burn-quick mix-lean burn combustor at elevated temperature and pressure," NASA/CR -2002-21192, 2002.

5. Lee, C.M., Bianco, J., Deur, J.M., and Ghorashi, B., "Nitric oxide formation in a lean premixed prevaporized Jet A/air flame tube: an experimental and analytical study," NASA/TM-2001-105722, 1992.

6. Tacina, R., Lee, P., and Wey, C., "A lean-direct-injection combustor using a 9 point swirl-venturi fuel injector," ISABE-2005-1106, 2005.

7. Tacina, R., Mao, C.-P., and Wey, C., "Experimental investigation of a multiplex fuel injector module with discrete jet swirlers for low emissions combustors," AIAA-2004-0135, 2004. 
8. Tacina, R., Wey, C., Laing, P., and Mansour, A., "A low-NOx lean-direct injection, multipoint integrated module combustor concept for advanced aircraft gas turbines," NASA/TM-2002-211347, 2005.

9. Bianco, J., "NASA Lewis Research Center's combustor test facilities and capabilities," AIAA-1995-2681, 1995.

10. Lefebvre, A.H. Gas Turbine Combustion, $2^{\text {nd }}$ ed., Taylor and Francis, Philadelphia, 1998.

11. Beer, J.M. and Chigier, N.A. Combustion Aerodynamics, $1^{\text {st }}$ ed., John Wiley \& Sons, Inc., New York, 1972.

12. IDL, Exelis Visual Information Solutions, Software Package, Ver. 8.3, Boulder, Colorado, 2013.

13. Feature.pro, John C. Crocker and David G. Grier, Emory University, Atlanta, Ga, 1996.

14. Gupta, A.K., Lilley, D.G., and Syred, N., Swirl Flows, Abacus Press, Kent, UK, 1984.

15. Fu, Y., "Aerodynamics and Combustion of Axial Swirlers," Ph.D. Dissertation, University of Cincinnati, 2008.

16. Ajmani, K., Mongia, H.C., and Lee, P., "Evaluation of CFD Best Practices for Combustor Design: Part I - Non-Reacting Flows," AIAA-2013-1144, 2013.

17. Hicks Y.R., Heath, C.M., Anderson, R.C., and Tacina, K.M. "Investigations of a combustor using a 9-point swirl-venturi fuel injector: recent experimental results," ISABE-2011-1106, 2011.

18. Alekseenko, S.V., Kuibin, P.A., Okulov, V.L., Theory of Concentrated Vortices, Springer-Verlag, Berlin, 2007.

19. Kilik, E., "The Influence of swirler design parameters on the aerodynamics of the downstream recirculation region." Ph. D. Dissertation, School of Mechanical Engineering, Cranfield Institute of Technology, 1976.

20. Bafuwa, G.G. and Maccalum, N.R.L, "Turbulent Swirling Flames Issuing from vane Swirlers," $18^{\text {th }}$ Meeting of Aerodynamics Panel, I.F.R.F. 1970. 

